\title{
Aprender a pesquisar: ato que ressignifica a aprendizagem e mobiliza a construção de novos saberes
}

\section{Learningto research: act that re-signifies learning and mobilizes the construction of new knowledge}

Solange Maria Rodrigues Alberto é pedagoga e coordena o Núcleo de Educação do Programa Einstein na Comunidade de Paraisópolis. É mestranda pelo Programa de Pós-Graduação em Ciências da Informação da Escola de Comunicações e Artes da USP.

Contato: solangemra2@gmail.com

\section{Resumo}

A metodologia de trabalho com pesquisa junto a crianças e adolescentes teve sua origem a partir das discussões sobre as práticas educacionais e as adversidades impostas no cotidiano, o que possibilitou reconfigurar o papel do educador como mediador de aprendizagens e sujeito que faz a mediação entre a informação e o conhecimento. Compreende-se o ato de aprender como a soma de experiências significativas, considerando processos educativos que se voltam para a apropriação de saberes informacionais na contemporaneidade. A atividade foi organizada na elaboração do Plano de Pesquisa Individual e como principal resultado destaca-se a experiência consolidada, que reafirma a necessária vinculação do sujeito com atos afirmativos e criativos e vem se mostrando eficaz em romper com o tradicionalismo, buscando referendar uma ação educativa que coloca sujeitos como protagonistas e criadores de cultura, ressignificando experiências e percursos.

Palavras-chave: educação, pesquisa, mediação, autonomia e dispositivos informacionais. 


\begin{abstract}
The work on researching had its origin from the discussions about educational practices and adversities imposed in daily life, which allowed reconfiguring the educator's role as a mediator of learning and as a subject that mediates information and knowledge. The discussion is comprehendedin the sense that the act of learning is the sum of significant experiences, considering educational processes focused on the appropriation of informational knowledge in contemporary times. The activity was organized in the elaboration of the Plan of Individual Research and as main result we found that experience consolidate and reaffirm the necessary binding of the subject to affirmative and creative acts and it has been effective in the sense of going through the traditionalism and aims to validate an educational action that puts subjects as protagonists and creators of culture, re-signifying experiences and paths.

Keywords: education, research, mediation, autonomy and informational devices.
\end{abstract}

Este relato de experiência se insere no quadro que pensa práticas e metodologias em consonância com abordagens educacionais voltadas para a aprendizagem de novos saberes informacionais na contemporaneidade. A busca por uma concepção de educação que pudesse subsidiar atos de criação e significação envolvidos nos processos de aprendizagem direcionou este estudo e mobilizou um grupo de educadores na construção de estratégias que pudessem se tornar referência para o trabalho com pesquisa. Muito se discute sobre os processos envolvidos no ato de pesquisar para se informar, uma vez que há hoje uma profusão de informações que circulam de forma veloz entre nós, propiciando acesso rápido a diferentes fontes e plataformas de pesquisa. No entanto, há outra discussão que se dedica a pensar não mais a circulação e a difusão, mas, principalmente, a maneira como o sujeito aprende, e pouco se avança na direção de se propor práticas que possam dialogar com a forma como as pessoas vêm se informando e se formando.

\section{Educação e Informação: aprender a conhecer}

A implantação da metodologia de pesquisa para as crianças e adolescentes do Programa Educação Cidadã do Programa Einstein na Comunidade de Paraisópolis - PECP ${ }^{1}$ teve sua inspiração inicial
1. O Programa Einstein na Comunidade de Paraisópolis surgiu inspirado nas ações da Sociedade Beneficente Israelita Brasileira Albert Einstein, sendo que um dos focos é o trabalho voltado às ações socioeducativas no Centro de Promoção e Atenção à Saúde - CPAS. 
nas propostas educacionais da escola da Ponte, em Portugal, a partir das leituras propiciadas pelo curso Fazer a Ponte no Brasil.

A busca por referenciais educacionais que pudessem subsidiar uma experiência de ensino baseada na autonomia do sujeito frente a sua aprendizagem e na gestão compartilhada propiciou conhecer o trabalho da Escola da Ponte, que tem como diretriz pedagógica o conceito de escola aberta e, segundo José Pacheco, idealizador do Projeto Escola da Ponte, "é área aberta de comunicação e colaboração dentro da escola, é área aberta para o meio e integração na comunidade" (PACHECO, 2010, p.108).

A abordagem deriva também da experiência vivida em Reggio Emilia (Itália/2010), por meio da participação no Grupo de Estudios desde Latinoamérica. A Pedagogia de Reggio Emilia traz os princípios de uma educação que considera o diálogo e a pesquisa permanentes das crianças com a cidade e tem no valor da subjetividade a sua expressão máxima. Tal vivência ampliou a visão de "Cidade Educadora; Comunidade de Aprendizagem", entendendo que novas leituras da cidade e do território poderiam ser feitas para se fazer a educação nesse contexto. Naquele momento, pensar uma forma de trabalho pedagógico que fosse inovador e que pudesse despertar nos participantes o desejo pelo conhecimento se apresentava como um grande desafio, uma vez que o Programa havia sido reformulado e o projeto educacional precisava ser diferenciado.

O Programa Educação Cidadã foi implantado em abril de 2004 e faz parte das ações socioeducativas do Centro de Promoção e Atenção à Saúde. Tem por objetivo contribuir para o desenvolvimento de habilidades em crianças e adolescentes que possibilitem uma participação comunitária e cidadã.

Após quatro anos de funcionamento, em 2008, realizou-se uma avaliação institucional, na qual se constatou que o modelo vigente sinalizava dificuldades na resolução dos conflitos intraescolares e familiares trazidos no cotidiano das atividades. A permanência das crianças apenas uma vez por semana nesse programa sugeria, também, a importância de um trabalho mais sistemático e contínuo, tanto do ponto de vista educacional com a melhora no desempenho escolar, o aumento do espaço para expressão, o maior envolvimento com as situações de aprendizagem e a mudança na postura de estudante - quanto das demandas relacionadas à situação de vulnerabilidade social, ou seja, às esferas de proteção, cuidado e acompanhamento familiar. Observou-se, ainda, dificuldade na apropriação da informação, 
tendo em vista que as práticas educativas e culturais precisavam ser revistas e traduzidas em experiências que pudessem "resgatar" o sentido do aprender para os sujeitos participantes, além de fatores limitantes para essa vivência, como a inconstância da permanência e a fragilidade de vínculos estabelecidos entre educador e educando.

Em virtude das demandas observadas no contexto de Paraisópolis e a partir do trabalho do PECP em parceria com organizações, profissionais e pais, alterações significativas na estrutura do Projeto foram realizadas em fevereiro de 2009: a frequência às atividades passou a ser diária e a faixa etária, que antes era de 7 a 10 anos, foi alterada para abranger crianças e jovens de 6 a 15 anos. A mudança se deu a partir da compreensão de que as crianças e adolescentes necessitavam de um espaço mais protegido e acolhedor e que pudesse, de fato, ser promotor de mudanças no desempenho escolar e cultural desses sujeitos e na resolução dos conflitos.

Na tentativa de construção do conceito de Educação Cidadã, essa experiência se inspira na pedagogia dialógica de Paulo Freire (1967, 1979 e 1993) e nos princípios metodológicos da Escola da Ponte (2003 e 2008) e de outras práticas inovadoras em educação no Brasil2 $^{2}$, a fim de criar uma vida coletiva pautada na ética e no respeito às diferenças, condições essenciais para a visão democrática da autonomia que se buscava construir.

O sentido da autonomia para o projeto é a construção de um novo caminho no qual se crie um modo de participação que leve em consideração as próprias contradições inerentes ao ambiente e promova uma participação democrática que permita ao sujeito um nível de autonomia frente ao conhecimento que, de acordo com Freire (1997), possa garantir que o ato de ler e escrever se traduza em um posicionamento crítico - leitura crítica do mundo - frente à realidade que se vive. Escrever e reescrever o mundo, a partir de sua própria leitura e critérios, significa transformá-lo.

Ser autônomo ou ter autonomia passa, também, por interrogar que tipo de relação tem o sujeito com a informação e esta precisa ser compreendida do ponto de vista de sua experiência, ou seja, como este compreende, critica, dialoga, conhece e atua sobre os diferentes processos da ordem informacional. Autonomia entendida, então, como a forma com que o sujeito compreende e usa a informação para criar significados.

Se, por um lado, entender o sujeito como autônomo e protagonista cria as bases para um modelo de educação
2. Entre as experiências, vale citar a EMEF Desembargador Amorim Lima (São Paulo) inspirada na experiência da Escola da Ponte (Portugal), com seus roteiros de estudo e professores tutores; e a Escola Lumiar São Paulo (São Paulo), com seu conceito de livre escolha, currículo em mosaico e professores tutores. 
enquanto prática transformadora, por outro, pensar os modos de formação e informação também estão no centro dessa reflexão, pois compreende-se que produzir conhecimento e cultura na contemporaneidade requer a reinvenção de um sistema de acesso à informação que possa ser traduzido em práticas culturais e de leitura que rompam com mecanismos transmissivistas e de oferta de objetos culturais, para se pensar práticas que permitam que o sujeito possa dialogar com a informação e apropriar-se dos significados culturais produzidos historicamente.

Nesse sentido, este artigo busca repensar os modos de produção de conhecimento na contemporaneidade, entendendo a necessária articulação entre Educação e Informação, e procura descrever uma experiência que vem sendo desenvolvida pela sua relevância e inovação na interface entre essas duas áreas: Aprender a Fazer Pesquisa.

A discussão se centra na questão sobre o que seja produzir conhecimento na atualidade e como os ambientes informacionais estão hoje organizados, uma vez que se constata, nessa era que se intitula "Sociedade da Informação", uma crescente preocupação com o fluxo da informação (identificação, armazenamento, processamento e acesso à informação) e que tem determinado os modos de vida e os relacionamentos profissionais.

A "Sociedade da Informação" vem se pautando por uma economia de informação, uma vez que predomina no sistema econômico produtivo a informação como mercadoria (visão fragmentadora). Há necessidade de uma reorganização dessa nova ordem, como tentativa de não gerar ou acentuar a marginalização e exclusão que são determinadas pelas relações econômicas que, ao longo do tempo, sobrepõem-se a uma visão humanista (LAZARTE, 2000).

Para contrapor a visão fragmentadora na compreensão do uso das tecnologias, a crescente explosão do fluxo de informação e seu "uso operacional" (relevante apenas para tomar decisões), Lazarte faz uma análise na qual aborda o processamento da informação dentro de um contexto em que não é a quantidade de informação que será determinante, mas sim a capacidade do sujeito de ignorar as informações que circulam com foco na escolha do que seja relevante. "Se os primeiros elementos do processo cognitivo estão relacionados com saber reconhecer, este reconhecimento só acontece porque simultaneamente sabemos ignorar o que não é relevante" (LAZARTE, 2000, p. 46). 
Edgar Morin, durante conferência proferida no Brasil em 2005, aponta também outros obstáculos implicados na maneira como a sociedade vê o conhecimento e defende a ideia de uma educação que tem por princípio a não separação de conhecimentos em disciplinas para apenas analisá-las, rompendo com a fragmentação que há hoje nos programas educativos (MORIN, 2002), mas a integração entre áreas, conhecimentos e fatores (econômicos, sociais etc.) para se compreender do global ao local e, assim, saber de que humanidade se fala.

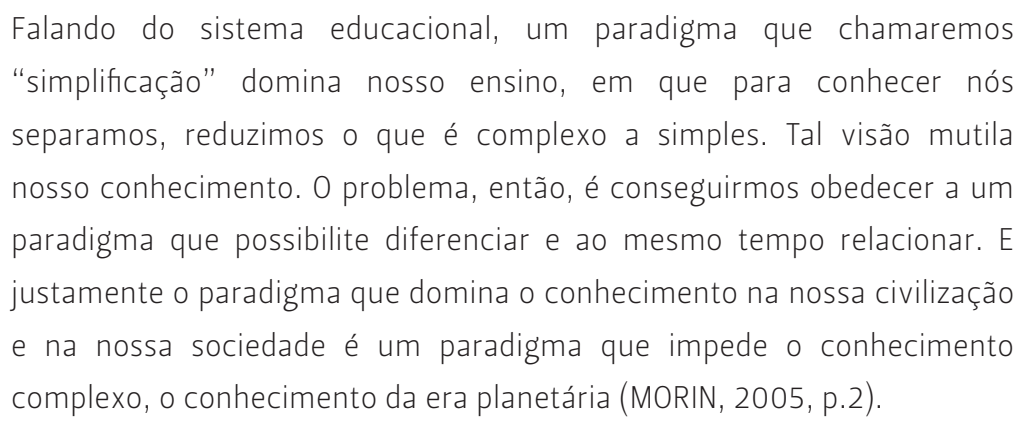

0 autor amplia a discussão para se pensar uma educação que tem por princípio a interação, em que coexistem conhecimentos e relações humanas, e afirma "[...] nós, indivíduos, produzimos a sociedade por nossas interações, mas a sociedade, com sua cultura, nos transforma em indivíduo plenamente humano" (MORIN, 2005, p.4).

Falar de conhecimento é falar de produção cultural. Está aqui posta outra questão que diz respeito aos saberes produzidos pela relação do sujeito com os objetos culturais. Que espaços e tempos estão hoje colocados e que permitem processos de criação e significação como condição da existência nesse mundo, uma vez que o tempo do fluxo da informação não é o mesmo que o tempo do conhecimento?

A busca por essa compreensão situa-se, inicialmente, no que os teóricos (GADOTTI, 2000; LAZARTE, 2000; PERROTTI; PIERUCCINI, 2008) definem como a transição da Sociedade da Informação para a Sociedade do Conhecimento, permitindo a criação de um novo ambiente informacional, uma vez que se constata que o acesso e a universalização da informação não têm contribuído para que o sujeito atue e produza processos de significação.

A questão apenas do ponto de vista do acesso tem imposto uma forma de atuação do sujeito como mero consumidor e espectador na medida em que adquire "objetos" para atender às suas necessidades de vida. É o caráter da utilidade imediata 
(imediatismo da vida) que se apresenta, desconsiderando os atos de significação.

Construir significado pressupõe uma relação entre presente e passado que diverge do imediatismo imposto pela modernidade. Onde entra a tradição? Seria a cultura a expressão máxima de criação de um povo e que possibilita que o "fio da tradição não se rompa"? A perda da tradição estaria impondo um modo de vida no qual o sujeito passa a julgar as questões do mundo pelo ponto de vista do privado e econômico, rompendo com as tradições e heranças do passado.

É essa a discussão que Arendt (1978) propõe ao analisar como o surgimento da sociedade de massas (cultura de massas) vem se contrapor a uma maneira de se educar por meio da apreciação da arte, impondo outro modo de receber cultura que não se traduz em consumo, ou seja, quando a arte e seus objetos culturais perdem o valor e sofrem modificação (adaptação/condensação) para atender a indústria de entretenimento, consumo rápido, gerando, como consequência, o empobrecimento na maneira de se relacionar com essa mesma cultura. É um modo de vida que vem sendo determinado pela sociedade de consumo e pela cultura vista como "valor de troca" e não mais como possibilidade de aprimoramento e status social.

Russel (2002) enfoca os riscos para a humanidade quando os indivíduos ficam concentrados em um único objetivo e não avaliam perdas, esquecendo-se de viver momentos de lazer (lúdicos) com o simples propósito do prazer imediato. 0 conflito entre o fazer (predomínio da técnica e da razão) e a sua obra (viver e expressar-se não tendo o trabalho como único foco) apresenta-se na contemporaneidade como algo que inibe e limita processos de significação. É nesse sentido que entra o papel da cultura como estado elevado em contraposição ao poder e à dominação, na argumentação de Russel:

A concepção estreitamente utilitária da educação ignora a necessidade de os indivíduos serem tão bem treinados em seus propósitos quanto em suas qualificações. A natureza humana não treinada contém um forte componente de crueldade, que se apresenta de várias formas, grandes e pequenas. [...] Não porque o refinamento mental produza sentimentos humanitários positivos, ainda que possa fazê-lo, mas porque cria outros interesses que não o de maltratar o próximo e fontes de autoestima que prescindem da afirmação pela dominação. [...] A cultura proporciona às pessoas formas menos nocivas de poder e meios mais dignos de se fazerem admiradas (RUSSEL, 2002,p.42-43). 
Para o autor, a contraposição dessa visão que ressignifica o papel do conhecimento "inútil" estaria no incentivo à "atividade mental contemplativa", entendida não como recepção passiva mas como outro jeito de se relacionar com o mundo, e conclui:

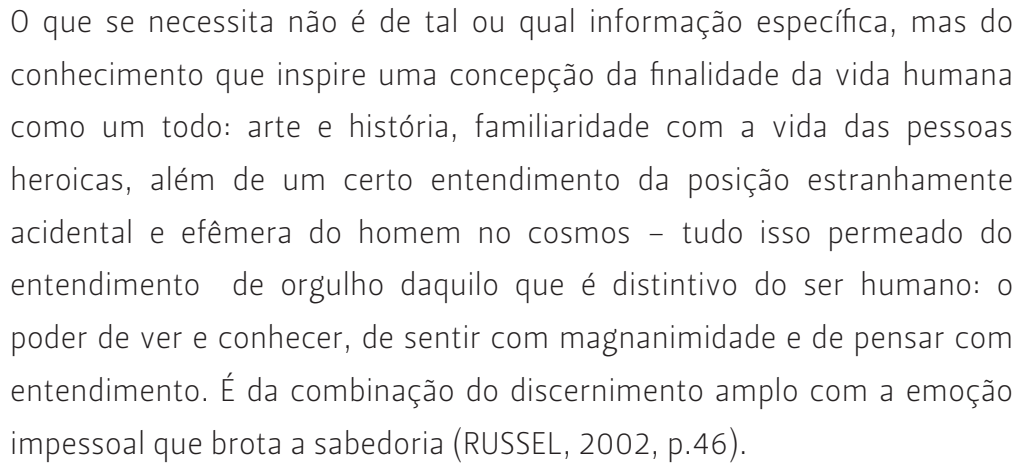

Estaria aqui a discussão sobre o fluxo e a velocidade da informação que estão determinando um modo de vida contemporâneo que define a relação com a informação inibindo processos de produção, criação e atribuição de sentidos. É o tempo do aprender que se transforma em habilidades para se conquistar ("ganhar a vida"). Nesse sentido, como processos educacionais que consideram o sujeito inserido em um mundo dominado pela explosão informacional e por recursos tecnológicos poderiam, ao mesmo tempo, produzir mecanismos que permitam não olhá-lo como simplesmente "competente" para acessar a informação?

Diante desse cenário, há necessidade de se criar um novo ambiente informacional que possa reduzir o desequilíbrio gerado pelo excesso de informação ("bombardeio informacional"), reorganizando o contexto de significados relevantes para o indivíduo, de forma a reagrupar em novas unidades de sentido os estímulos recebidos.

Os princípios norteadores desse projeto se apoiam nos eixos educacionais propostos pelo relatório da Unesco produzido por Jacques Delors (1998), no capítulo em que menciona Os quatro pilares da Educação. Tal diretriz se apresentou como uma referência para o trabalho pedagógico e as quatro aprendizagens foram traduzidas em ações no contexto da Educação Cidadã. Faltava materializar o Aprender a Conhecer e, como aponta o autor:

Este tipo de aprendizagem que visa nem tanto a aquisição de um repertório de saberes codificados, mas antes o domínio dos próprios instrumentos do conhecimento pode ser considerado, simultaneamente, como um meio e uma finalidade da vida humana. [...] a tendência para prolongar a 
escolaridade e o tempo livre deveria levar os adultos a apreciar, cada vez mais, as alegrias do conhecimento e da pesquisa individual. [...] é essencial que cada criança, esteja onde estiver, possa ter acesso, de forma adequada, às metodologias científicas de modo a tornar-se para toda a vida "amiga da ciência" (DELORS, 1998, p.90).

Fala-se muito hoje na função dos processos educativos não mais somente sob o ponto de vista de quem ensina ou de quem aprende, e sim na aprendizagem da partilha. Partilhar saberes, partilhar experiências de vida, partilhar ideias e partilhar a possibilidade de se reinventar enquanto educador têm se colocado como atitudes que permitem ressignificar experiências e novos modos de educar e de formar sujeitos.

Foi pensando nos desafios colocados para o fazer educacional na atualidade que se buscou a criação de uma metodologia pautada no aprender a usar a informação para a construção de novos modos de apropriação e significação. E aqui se incluem não só as discussões sobre os processos de ensino-aprendizagem como, principalmente, a possibilidade de se revisitar práticas educativas que permitissem que a criança e o adolescente construíssem um percurso, tendo o educador como mediador entre a informação e o conhecimento. Nesse sentido, fez-se necessário construir novas práticas; aprender a fazer pesquisa foi o caminho escolhido. Tal abordagem combina a aprendizagem de conteúdos com o desenvolvimento de competências, habilidades e atitudes para o uso dos diferentes dispositivos informacionais.

\section{Práticas e saberes partilhados: o lugar do mediador cultural}

Produzir conhecimento e cultura na contemporaneidade requer a reinvenção de um sistema de informação que possa dialogar com as práticas culturais e com o contexto da comunidade. Em Perrotti e Verdini (2008) e Pieruccini (2004) encontra-se a fundamentação teórica para o ambiente de Infoeducação Estação do Conhecimento Einstein, que foi implantado no PEPC, na Comunidade de Paraisópolis, em agosto de 2009, por meio da parceria com a equipe do Colaboratório de Infoeducação da Escola de Comunicações e Artes - ECA/USP, que tem a mediação cultural dialógica como abordagem central para a construção de saberes e apropriação cultural.

A Infoeducação se apresenta como nova área que se propõe a discutir os mecanismos de apropriação do conhecimento e cultura em face de uma nova ordem informacional que rompe 
com o pragmatismo e a linearidade dos processos educativos (informativos) e permite repensar a educação frente a processos norteados por sentidos, significados e valores.

A questão central da Infoeducação se localiza na forma como o sujeito inserido em um contexto que ainda se pauta pela lógica da produção e da competência pode acessar a informação disponível, circulante, e até excessiva, como possibilidade de inverter esta lógica, ressignificando a sua experiência. Entram em cena os saberes informacionais que precisam ser conhecidos, aprendidos e ensinados (PERROTTI; PIERUCCINI, 2013).

A análise da literatura a respeito de estratégias para o trabalho com a metodologia de pesquisa abriu possibilidades para pensar uma proposta cujo alicerce seria a pesquisa participativa e colaborativa, uma vez que a criança e o adolescente se colocariam no papel de pesquisador e protagonista do seu saber em diálogo com a educadora, esta agora no papel de mediadora e orientadora de estudo.

Fizeram parte dessa experiência 120 crianças e adolescentes na faixa etária de 6 a 15 anos que frequentam as escolas públicas da Comunidade de Paraisópolis, na cidade de São Paulo, e do seu entorno e, no período oposto ao escolar, participam do Programa Educação Cidadã. A equipe de profissionais é composta por uma pedagoga (Coordenadora do Programa), seis educadoras, quatro educadoras assistentes e duas educadoras com funções de mediadoras de leitura, que trabalham no ambiente da Estação do Conhecimento Einstein.

As leituras nos davam pistas de possíveis caminhos: valorizar a crítica, o diálogo e a participação de todos; promover uma vida coletiva baseada na confiança mútua, na participação e na resolução dialogada dos conflitos; valorizar a cooperação e favorecer o trabalho em equipe. Muitos questionamentos e caminhos apontavam a necessidade de mudança: que lugar a aprendizagem ocupa na vida dessas crianças e adolescentes? Onde se localiza o desejo por aprender? A busca por uma prática não escolarizada e que permitisse a liberdade de fazer escolhas e assumir responsabilidades estava no centro dos diálogos com a equipe.

Buscava-se uma nova forma de intervenção que pudesse favorecer o aprendizado da convivência democrática, o reconhecimento das diferenças e o exercício da igualdade dentro de um contexto educacional no qual os dispositivos 
metodológicos seriam estabelecidos em conjunto com todos os envolvidos nessa ação educativa. Os espaços para o diálogo e para a escuta precisavam ser construídos dentro de uma dinâmica na qual cada um se responsabiliza pelo papel que ocupa nessa rede de interação. 0 olhar atento sobre o cotidiano das relações, com ênfase no trabalho coletivo, é o que permitiria que novos vínculos institucionais e novos processos de aprendizagem fossem construídos.

0 primeiro encaminhamento foi criar um espaço de reflexão junto ao grupo de educadores, profissionais e voluntários que iriam atuar no Programa, cuja intenção era ouvir essa equipe a fim de se definir os pressupostos educacionais. Um diálogo com os agentes daquela ação foi estabelecido, dando voz para que se posicionassem. Encontros foram realizados e se tornaram uma importante prática, até então inexistente dentro da instituição: a criação de um espaço mensal permanente de formação com essa equipe.

Um conceito-chave no trabalho foi a construção do papel do educador como mediador cultural e que se fundamenta nos princípios da negociação e da colaboração, pressupondo: não ser aquele que facilita e traduz, mas quem acompanha o processo; mobilizar recursos para que a aprendizagem aconteça; ajudar a criança a construir seu próprio percurso educativo e a se planejar; propiciar mudanças nas atitudes, posturas e valores; e colaborar para que o sujeito construa seu conhecimento e adquira novos saberes por meio de um processo de autoria e protagonismo.

Até encontrar "o tom e a nota certa", foram muitos os momentos em que a equipe "desafinou". Durante o primeiro ano do projeto, o que movia a equipe era o desejo de mudança. A favor, houve o envolvimento, a dedicação e a persistência por parte das educadoras; porém, a realidade se apresentava com grandes desafios e que estavam sendo traduzidos, por parte das crianças e adolescentes, em resistência, negação e agressividade, atitudes estas que foram interpretadas como necessidades de pertencimento, acolhimento e superação. Fazia-se necessário um ambiente promotor de novas aprendizagens.

As atividades de pesquisa foram definidas por meio da implantação de uma proposta intitulada Plano de Pesquisa Quinzenal. Cada criança e adolescente escolhia seu tema de pesquisa, levantando três perguntas acerca desse assunto e as registrava em um documento (Escrita do Plano de Pesquisa). A execução do plano compreendia a busca de informações em 
diferentes fontes de pesquisa, incluindo aspectos diversos da aprendizagem, como a descoberta, o diálogo, o registro e, por último, a autoavaliação.

Como conclusão da primeira fase, chamada de Diagnóstica, após um mês de implantação da metodologia, pode-se destacar que o período foi importante para se compreender o que as crianças e adolescentes sabiam sobre pesquisa, como utilizavam os recursos disponíveis e as fontes de pesquisa, e que conhecimentos tinham sobre a leitura e a escrita. Por outro lado, aspectos não tão palpáveis, como interação, trocas, vivências, saber compartilhado, levantamento de necessidades, limites e possibilidades, contato com os recursos próprios ou que pode ser adquirido pela experiência do outro, marcaram a grande adaptação frente ao novo, tanto para as crianças e adolescentes, quanto - e principalmente - para as educadoras.

Dentre os principais pontos que foram observados nessa fase diagnóstica, vale ressaltar: a receptividade por parte das educadoras e crianças; a metodologia, que se apresentava como uma prática adequada e eficiente, em que se observava envolvimento, entusiasmo, cooperação e troca; e grupos com idades diferentes utilizando o mesmo espaço físico. Um conjunto de saberes começou a ser construído com os objetos culturais articulados em diálogo com as dinâmicas de apropriação, considerando-se a necessária integração entre pensamento, sentimentos, emoções, afetos, memória cultural e valores éticos.

0 que se propôs, na sequência, foi o trabalho com uma segunda fase, chamada de Instrumentalização. Iniciou-se o que foi nomeado como "Aprendendo a Pesquisar". Cada educadora planejou uma sequência de atividades em que se buscou socializar as práticas entre a equipe, assim como oferecer subsídios para que os grupos conhecessem mais sobre os procedimentos e técnicas de pesquisa. Fazia-se necessário "aprender a aprender" e o caminho escolhido foi a troca de saberes entre as educadoras e entre os grupos de educandos.

Nesse período de intensa pesquisa e estudo por parte da equipe sobre a metodologia, o diálogo e a parceria existente com a equipe dos professores Drs. Edmir Perrotti e Ivete Pieruccini, da Escola de Comunicações e Artes da Universidade de São Paulo (ECA-USP), possibilitaram ampliar a discussão para se pensar os processos de apropriação de saberes informacionais com foco no papel da mediação cultural. Um curso sobre o trabalho com pesquisa e uso dos diferentes dispositivos informacionais foi significativo e 
permitiu recolocar no centro do debate com a equipe as estratégias de se "conhecer o conhecimento" e de se constituir um processo apoiado pelo facilitador no encaminhamento da pesquisa, com respostas dialogadas de maneira transdisciplinar. Circulando por vários suportes informacionais e dispositivos, pode-se avançar para a construção de uma educação que tem a ação afirmativa como parte desse processo de participação no mundo do conhecimento e da cultura (PERROTTI; PIERUCCINI, 2013).

Algumas mudanças foram pensadas: planejar uma apresentação dos resultados dos planos (compartilhar saberes); cada grupo caminharia em conjunto, a cada etapa da pesquisa; o acompanhamento deveria ser mais individualizado, para garantir o cumprimento do plano e que a informação pudesse ser, de fato, transformada em conhecimento, ou seja, em aprendizagem significativa; cada educadora se responsabilizaria por um grupo de crianças (mediadoras-tutoras), facilitando para que o sujeito encontre os caminhos para se tornar autônomo e aprenda a tomar decisões.

Trabalhar com essa metodologia permitiu não apenas olhar para as competências e habilidades implicadas no processo de apropriação de saberes operacionais, mas, principalmente, proporcionou o desenvolvimento de atitudes na construção de um percurso que permite que o sujeito aprenda, e se constitua para intervir na realidade - saber, ser e estar no mundo.

Muitas outras reflexões e avaliações se seguiram a essas, sempre pautadas na observação do contexto, tais como: percepções das educadoras, análises das produções, avaliação dos resultados e relatos dos grupos. 0 que se buscou foram adaptações no tempo e na sequência da execução do plano, visando, acima de tudo, a compreensão de que o "tempo" não deveria ser o marcado pelo relógio, do conhecimento "útil", da aquisição da informação no sentido de "cumprir a tarefa em menor tempo", como bem coloca Bosi (2001), ao refletir sobre os usos e sentidos do tempo nomeado como tempo aberto e livre, antes da pesquisa e depois da informação adquirida. 
Essa proposta, definida como Plano de Pesquisa Individual, é composta por sete diferentes momentos para efeitos do gerenciamento de estudo:

1a etapa: seleção do tema (objeto de estudo).

$2^{\text {a }}$ etapa: escrita do plano (levantamento de perguntas e hipóteses): a criança assume esse compromisso junto ao educador, em um processo de corresponsabilização por tal tarefa.

3a etapa: busca de materiais: seleção das obras no acervo do espaço da Estação do Conhecimento Einstein.

4a etapa: desenvolvimento da pesquisa nos diferentes ambientes do Programa com orientação de mediadores tutores: Espaços de Pesquisa, Estação do Conhecimento e no Laboratório de Informática.

5a etapa: elaboração do produto para exposição: o saber que se torna comunicável.

6a etapa: processo de autoavaliação sobre o desenvolvimento da pesquisa como resposta às seguintes questões: 0 que mais gostei de descobrir? Que dificuldades encontrei durante a pesquisa? Por quê? 0 que posso fazer para diminuir as dificuldades encontradas? A educadora participa desse momento comentando as suas percepções sobre o desempenho do pesquisador.

7a etapa: compartilhando nossas descobertas: exposição nas dependências do Programa, com convite aberto à comunidade e familiares como possibilidade de socializar os saberes adquiridos.

Se, por um lado, havia um direcionamento para a construção das práticas, por outro estava presente uma preocupação em se criar uma forma de avaliação que pudesse ser formativa e que, de fato, trouxesse contribuições sobre o processo de pesquisa de cada participante, apontando conquistas, avanços e sinalizando as dificuldades inerentes ao ato de pesquisar. Instrumentos avaliativos e indicadores foram elaborados: crianças e adolescentes demonstrando envolvimento na elaboração das pesquisas, aprendendo a fazer pesquisas e apresentando melhora na leitura e na escrita. 


\section{Educação: ato de protagonismo}

Como principais resultados, vale destacar a consolidação da proposta após quatro anos de trabalho. A busca da abordagem investigativa por parte das crianças e adolescentes, o desejo por conhecer algo novo e o despertar da curiosidade se mostraram presentes nos resultados dos trabalhos e só foram possíveis com a sistematização de uma prática colaborativa por parte da equipe de educadoras e de intensa observação e reflexão sobre o cotidiano. Para Madalena Freire (2008), os registros reflexivos permitem ao educador armazenar informações sobre o objeto em estudo para transformá-lo.

Uma nova pergunta se colocava para a equipe: E o valor dessa experiência? Outras conexões, outro lugar e um saber construído por uma equipe que se lança em uma nova jornada, driblando as adversidades do contexto como, por exemplo, a afirmação de que "Estudar e fazer tarefa são atividades da escola", escola esta que ainda se pauta por processos de transmissão de saber e "Pesquisa para quê? Eu não quero saber nada!", atitudes que foram sendo lidas como desafios e não como barreiras. Para o educador, o desafio de aprender a lidar com os excessos de informação, de opinião, de falta de tempo e do trabalho que, como aponta Bondía, impossibilitam que o sujeito viva a experiência.

\footnotetext{
Esse sujeito que não é o sujeito da informação, da opinião, do trabalho, que não é o sujeito do saber, do julgar, do fazer, do poder, do querer. [...] o sujeito da experiência se define não por sua atividade, mas por sua passividade, por sua receptividade, por sua disponibilidade, por sua abertura (BONDÍA, 2002, p.24).
}

A construção de um espaço permanente de formação com a equipe permitiu a construção desse trabalho colaborativo, com ênfase na elaboração dos procedimentos de forma compartilhada. Foram os dados de observação da própria prática, com regulações constantes entre falas, atitudes, questionamentos e procedimentos, que permitiu envolver a equipe na construção de algo que pudesse transformar a realidade presente. Transformação essa que permitiu que crianças, adolescentes e educadores vivessem uma experiência única e singular.

Os dados avaliativos ${ }^{3}$ apontam que $81 \%$ dos participantes da Educação Cidadã se envolvem com o processo de pesquisa. Esse indicador revela um crescimento significativo se comparado aos números apresentados nos três últimos anos (média de $73 \%$ ), o que permite constatar que a metodologia de pesquisa favorece
3. Fonte: Relatório Anual do Programa Einstein na Comunidade de Paraisópolis (2013). Dados gerados e formalizados pela equipe técnica do Programa. 
e desenvolve no sujeito um maior envolvimento com o ato de aprender para adquirir conhecimento.

Ainda como um importante resultado, vale apontar que a proposta definida como Aprendendo a Pesquisar se transformou em uma oficina que é oferecida para todas as crianças de seis a oito anos que ingressam no Programa, cuja finalidade é permitir a vivência da pesquisa por meio do acesso e uso dos diferentes dispositivos informacionais, antes de desenvolver o seu primeiro plano de pesquisa.

Como análise final, considera-se que essa experiência consolida e reafirma a necessária vinculação do sujeito com atos afirmativos e criativos. Há pontos a serem destacados que dizem respeito à forma como o processo da pesquisa é conduzido e se insere no quadro de pensar a construção de novos modos do sujeito se relacionar com a informação e produzir conhecimento enquanto ato de significação. Tal metodologia constrói e reconstrói processos educativos, tendo o sujeito como protagonista dessa ação, e aponta os saberes envolvidos:

- Saber perguntar, questionar-se e interrogar-se na busca de respostas e de sentidos para o ato de aprender. Aprender a ignorar o que não é relevante.

- Etapas do processo não se determinam pelo fluxo da informação e sim pelo tempo do conhecimento.

- Saber não se fragmenta e deve integrar áreas, contemplando uma visão transdisciplinar.

- Processos de criação e significação (construção da subjetividade) que permite ao sujeito ter uma postura não de "receptor", mas de criador e, com isso, se transformar e transformar a realidade.

- Conhecimento entendido como produção cultural: produtos elaborados para a exposição "Compartilhando Nossas Descobertas" não são apenas "construções pedagógicas", mas produções com valor cultural expresso em significados e valores.

- Fazer que se transforma em "obra de arte".

- Mediação cultural como a possibilidade de diálogo entre informação e conhecimento: educador que se coloca "entre" o saber e seus educandos, e cria pontes. Permite o acesso aos dispositivos e colabora para que o sujeito aprenda a usar as ferramentas de busca e avance para estabelecer 
novas conexões e relações com a informação (acesso, uso e ressignificação de sentidos).

- Experiência vivida, partilhada, significada e ressignificada em um processo de rede de interações.

A Educação Cidadã vem, assim, se constituindo para que as crianças e adolescentes se tornem sujeitos autônomos, protagonistas de suas próprias histórias e percursos educativos, em um constante processo de apropriação, negociação cultural e diálogo. Tal metodologia, baseada nos princípios de aprender a se informar, permite ao sujeito da experiência uma vivência frente ao conhecimento que determinará seus modos de saber, ser e estar no mundo.

\section{REFERÊNCIAS}

ARENDT, H. A crise da cultura. In: Entre o passado e o futuro. São Paulo: Perspectiva, 1978.

BONDÍA, J.L. Notas sobre a experiência e o saber de experiência. Revista Brasileira de Educação, n. 19, p. 20-28, jan/abr, 2002.

BOSI, A. Considerações sobre tempo e informação. Redemoinhos, São Paulo, jul. 2001. Disponível em: <http:// www.iea.usp.br/publicacoes/textos/bosiinternet.pdf>. Acesso em: maio 2004.

DELORS, J. (org.). Educação um tesouro a descobrir Relatório para a Unesco da Comissão Internacional sobre Educação para o Século XXI. Editora Cortez, 1998. Disponível em: http://dhnet.org.br/dados/relatorios/a_pdf/r_unesco_ educ_tesouro_descobrir.pdf. Acesso em: 04 de abril de 2008.

FREIRE, M. Educador, educa a dor. São Paulo: Paz e Terra, 2008.

FREIRE, P. Pedagogia da autonomia. São Paulo: Paz e Terra, 1997. 
Educação como prática da liberdade. Rio de Janeiro: Editora Paz e Terra, 1967.

Educação e mudança. São Paulo: Editora Paz e Terra, 1979.

Política e educação. São Paulo: Cortez Editora, 1993.

GADOTTI, M. Perspectivas atuais da educação. São Paulo Perspec., São Paulo, v. 14, n. 2 jun. 2000. Disponível em: http://www.scielo.br/scielo.php?script=sci_ arttext\&pid =S0102-88392000000200002\&lng=en\&nrm=iso . Acesso em: 22 ago. 2009.

LAZARTE, L. Ecologia cognitiva na Sociedade da Informação. Ciência da Informação, Brasília, v. 29, n. 2, p. 43-51, maio/ ago. 2000.

MORIN, E. Os sete saberes necessários à educação do futuro. São Paulo: Cortez, 2002.

Educação planetária: conferência na Universidade São Marcos, São Paulo, Brasil, 2005. Disponível em: <http:// edgarmorin.org.br/textos.php?tx=30>. Acesso em: 5 ago. 2012.

PACHECO, J. Escola da Ponte: formação e transformação da educação. Petrópolis: Vozes, 2010.

PERROTTI, E.; PIERUCCINI, I. Infoeducação : saberes e fazeres da contemporaneidade. In : LARA, M.L.G, FUJINO, A. NORONHA, D.P. (orgs) Informação e contemporaneidade: perspectivas. Recife: Néctar, 2008.p.46-97

Novos saberes para o século XXI. In: MENDONÇA, R.H.; MARTINS, M. F. (orgs.). Novos saberes para a Educação. Rio de Janeiro: ACERP; Brasília, DF: TV Escola, 2013. p. 9-25 (TV, educação e formação de professores: salto para o futuro 20 anos, 4). Disponível em: <http://tvescola.mec.gov.br/ images/stories/publicacoes/salto_para_o_futuro/salto_20 _anos/vol_4_salto_para_o_futuro_20_anos.pdf>. Acesso em: 20 fev. 2014. 
PIERUCCINI, I. A informação. In: A ordem

informacional dialógica: estudo sobre a busca de informação em Educação. São Paulo. 2004. 194f. Tese (Doutorado) Escola de Comunicações e Artes, Universidade de São Paulo, São Paulo.

PERROTTI, E.; VERDINI, A. S. Estações do Conhecimento: espaços e saberes informacionais. Boletim Salto para o Futuro, v. 18, p.45-65, 2008.

RUSSEL, B. O conhecimento inútil. In: O elogio ao ócio. Rio de Janeiro: Sextante, 2002.

Recebido em: 04/03/2015

Aprovado em: 04/05/2015 